\title{
Bloqueo neuromuscular prolongado tras dosis de secuencia rápida con rocuronio en paciente con enfermedad de Chagas
}

\author{
Sagastume I. ${ }^{1}$, Slavkin D. ${ }^{1}$ \\ 1 Hospital General de Agudos Dr. Cosme Argerich, CABA, Argentina.
}

Introducción: El bromuro de rocuronio es un fármaco aminoesteroide que actúa como bloqueante neuromuscular no despolarizante, cuya principal ventaja radica en su rápido inicio de acción (60-90 segundos) dependiendo de la dosis. Esta característica ha permitido su utilización como alternativa a la succinilcolina en la inducción de secuencia rápida sin los efectos adversos asociados a esta droga.

Descripción del caso: Paciente masculino de 68 años, $86 \mathrm{~kg}, 1,74 \mathrm{~m}$, ASA 3 que ingresa por guardia con diagnóstico de oclusión y perforación intestinal e indicación de colectomía total de urgencia. Como antecedentes refiere enfermedad de Chagas y diagnóstico de megacolon chagásico en 2016, sin cardiopatía asociada (ECG: bloqueo de rama derecha); hipertensión arterial y dislipemia con buena respuesta al tratamiento farmacológico. Se decide realizar secuencia rápida de intubación utilizando $3 \mathrm{mcg} / \mathrm{kg}$ de fentanilo, $2 \mathrm{mg} / \mathrm{kg}$ de propofol y $1,2 \mathrm{mg} / \mathrm{kg}$ de rocuronio y posteriormente realizar mantenimiento con anestesia balanceada (sevofluorano $1 \%$ y remifentanilo $0,5 \mathrm{mcg} / \mathrm{kg} / \mathrm{min}$ ).

El monitoreo de relajación neuromuscular se llevó a cabo mediante el S/5 M-NMT NeuroMuscular Transmission Module (Datex-Ohmeda, Madison, WI). Se realizó la calibración correspondiente previo a la relajación muscular. Los registros posteriores a la administración de rocuronio mostraron valores compatibles con bloqueo muscular intenso (TOF 0, PTC 0) que persistieron durante toda la cirugía $(4 \mathrm{~h})$ sin haberse administrado reinyecciones.

Antes de despertar, se decidió administrar $8 \mathrm{mg} / \mathrm{kg}$ de sugammadex obteniendo una reversión transitoria de la relajación. Partiendo de un bloqueo intenso (TOF 0), tras la administración del antagonista se alcanzaron valores compatibles con bloqueo moderado (TOF $>1$ ), profundizándose nuevamente trascurridos 2 minutos de reversión. En consecuencia, se decidió administrar nuevamente la dosis de $8 \mathrm{mg} / \mathrm{kg}$ (alcanzando $16 \mathrm{mg} / \mathrm{kg}$ ) consiguiéndose un TOF 4 con relación del $95 \%$ que permitió una extubación exitosa.

Información adicional: Tras la administración intravenosa de bolo único de rocuronio en adultos sanos, la vida media de eliminación promedia los 66-80 minutos, el volumen aparente de distribución es de 193-214 $\mathrm{ml} / \mathrm{kg}$ y el aclaramiento plasmático ronda los 3,5-3,9 $\mathrm{ml} / \mathrm{kg} / \mathrm{min}$ sin la aparición de metabolitos producto del proceso de biotransformación. Sin embargo, existe una gran variablidad entre paciente ateniendo a enfermedades multiorgánicas o características individuales que podrían aumentar la vida media de eliminación a $21 \mathrm{~h}$ y disminuir el aclaramiento a $2,1 \mathrm{ml} / \mathrm{kg} / \mathrm{min}$.

La enfermedad de Chagas podría ser una de las patologías capaces de alterar la cinética esperada del rocuronio haciendo prácticamente imposible anticipar o prever la duración de su efecto por lo que resaltamos nuevamente lo importante que es el monitoreo rutinario de la relajación neuromuscular.

https://doi.org/10.25237/congresoclasa2019.42 